\title{
A study of atrazine adsorption by using the rice straw synthesized adsorbent
}

\author{
Thachanan Samanmulya ${ }^{1, *}$, Pawinee Deetae $^{2}$ and Patthranit Wongpromrat $^{1}$ \\ ${ }^{1}$ Chemical Engineering Department, Faculty of Engineering, King Mongkut's Institute of Technology Ladkrabang, Bangkok, Thailand \\ ${ }^{2}$ Food Fermentation Department, Faculty of Agro-Industry, King Mongkut's Institute of Technology Ladkrabang, Bangkok, Thailand
}

\begin{abstract}
This study focused on adsorption of atrazine in adsorbent synthesized from Rice Straw. Rice Straw biochar were used in the study as they exhibited significantly high adsorption capacity for pesticide. Briefly, rice straw was pyrolysis at $600{ }^{\circ} \mathrm{C}$ under nitrogen then biochar was modified using $\mathrm{H}_{3} \mathrm{PO}_{4}$. Biochar were characterized for their physico-chemical characteristics. The elemental analysis of biochar was performed using CHNS Analysis. The surface area and pore volume of adsorbents were estimated using the Brunauer, Emmett, and Teller (BET Analysis). In parts of Batch adsorption experiments was performed in range of room temperature and were divided to 2 parts. Part 1: Study of the kinetics adsorption was investigated using two models, namely, the pseudo-first-order and the pseudo-second-order models. Part 2: study of Adsorption isotherms. The results of CHNS analysis shows the elemental analysis that $51.795 \%$ of $\mathrm{C}, 0.763 \%$ of $\mathrm{H}, 1.634 \%$ of $\mathrm{N}$ and $0.654 \%$ of $\mathrm{S}$ and the result of BET Analysis shows the surface area is $372.4 \mathrm{~m}^{2} / \mathrm{g}$ and pore volume of adsorbents is $0.315 \mathrm{~cm}^{3}$. From plotting between $\mathrm{q}_{\mathrm{t}}(\mathrm{mg} / \mathrm{g})$ and time $(t)$ shows the dynamics of the adsorption of atrazine onto the biochar at $15 \mathrm{ppm}$ of initial atrazine concentrations. In general, atrazine was adsorbed quickly around 1-30 min. This could be due to fast mass transfer of solute from the solution to surface of adsorbent $s$ as a result of concentration gradient of the solute. The study of the kinetics adsorption showed that the pseudo-second-order model best described the adsorption which agrees with chemisorption as the rate controlling mechanism.
\end{abstract}

\section{Introduction}

Nowadays, an increasing worldwide consumption of fossil resources has not only led to a major shortage of energy resources but also accelerated the global warming and environmental problems. Many researchers have pointed out and made societal change towards more sustainable resources. One approach to reduce the use of fossil resource is the utilization of biomass materials, which is renewable and carbon neutral energy resource. Agricultural waste has contained a high percentage of carbon content that can be biomass materials candidate which is interested to produce energy, materials and chemicals instead of fossil resource. Almost of agricultural waste has brunt in the fields after harvest and its leads to produce emissions which can adverse to human respiratory and health.

Rice is a primary source of carbohydrates in many parts of the world, especially in Asia. Every kilogram of harvested rice gains a lot of straw wastes. Thailand is one of the biggest rice producers and the generated rice straw waste approximately $90 \%$ is abandoned. Due to a high availability, low or no cost and literal renewability, Biochar production would decrease the numbers of abundant rice straw towards the idea of "waste to wealth".
Currently, Thailand has a tendency of the use of pesticides in agricultural. 2010-2011, RASFF (Rapid Alert System for Food) of the EU had shown that atrazine, a kind of pesticide, was found in the agricultural products of Thailand about 55 times which were the highest number of detection comparing with the products from other countries. In addition, atrazine affects an environment and causes cancer and hormonal toxicity. As agriculture is the main industry in Thailand and there is a contamination of atrazine in water sources therefore the management of atrazine in water is necessary.

Atrazine molecule structure is shown in Fig. 1 and all above mentioned is reasons for our investigation of biochar production from rice straw to synthesize the adsorbent. The study of method for removing atrazine from water is also being offered.<smiles>CCNc1nc(Cl)nc(NC(C)C)n1</smiles>

Fig. 1. Molecule structure of Atrazine. 


\section{Experimental}

\subsection{Biochar production procedure}

Rice Straw raw materials are dried at $60{ }^{\circ} \mathrm{C}$ for $24 \mathrm{hrs}$. The dried rice straw was pyrolysis at $600{ }^{\circ} \mathrm{C}$ for $1 \mathrm{hr}$. under nitrogen gas and then ground to be a powder. Only $150-250$ mesh size was used and heated in $\mathrm{H}_{3} \mathrm{PO}_{4}$ at 80 ${ }^{\circ} \mathrm{C}$ for $1 \mathrm{hr}$. After it cooled down for $24 \mathrm{hrs}$, biochar was filtrated, washed until neutral and dried before using.

\subsection{Biochar characterization}

The elemental analysis of biochar was performed using CHNS Analysis. The surface area and pore volume of adsorbents were estimated using the Brunauer, Emmett, and Teller (BET Analysis).

\subsection{Adsorption experiments procedure}

Atrazine solution was prepared at the desired concentration. A fixed amount of biochar was put in the atrazine solution and stirred. Each samples were took with the varied time in a range of $2-300 \mathrm{mins}$ and filtrated. Gas Chromatography Mass Spectrometry quantified the amount of atrazine in sampling solutions.

\section{Results and discussion}

\subsection{CHNS analysis}

Elemental compositions of our synthesized adsorbent were qualified and quantified by CHNS analyser and shown in Fig. 2. Figure 2 is also shown a comparison with others synthesized adsorbents. Carbon content of our synthesized adsorbent is in a good range when compared with others works [1-3].

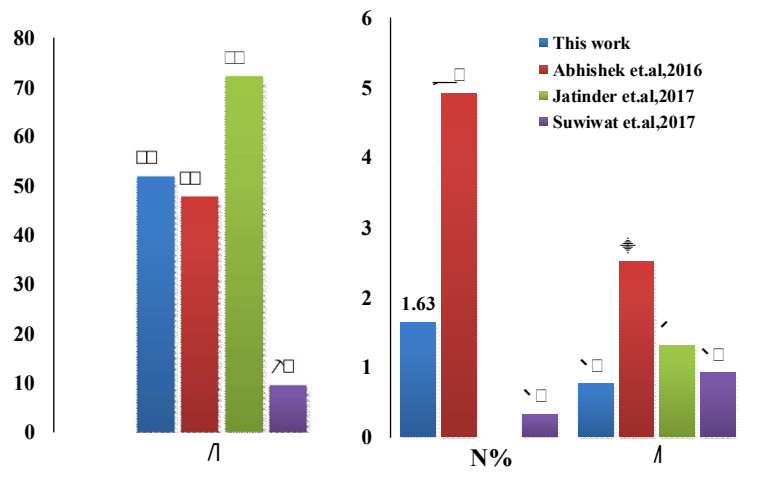

Fig. 2 Elements comparison of synthesized adsorbents.

\subsection{BET analysis}

BET analysis shows the surface area of $372.4 \mathrm{~m}^{2} / \mathrm{g}$ and pore volume of $0.315 \mathrm{~cm}^{3}$ for our synthesized adsorbent. Figure 3 is also shown a comparison of BET analysis with other adsorbents. Our synthesized adsorbent shows the highest values of surface area and pore volume when compared with other adsorbents [1-3]. It realized that our synthesized adsorbent from rice straw can be a good candidate for adsorption.

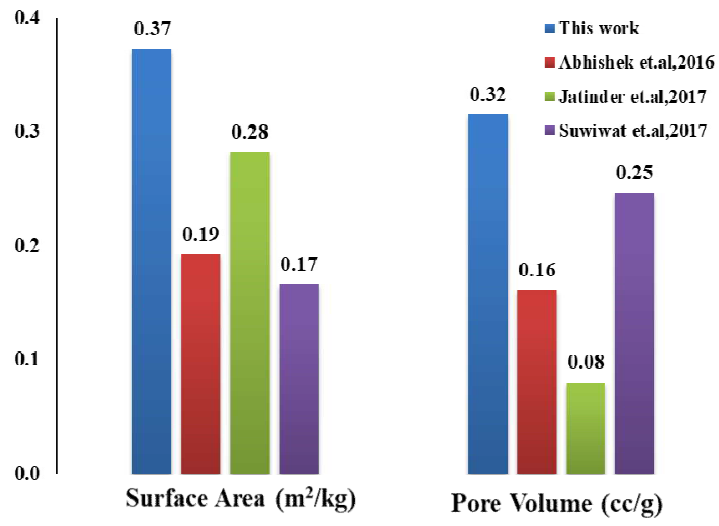

Fig. 3 Surface are and pore volume comparison of synthesized adsorbents.

\subsection{Atrazine adsorption}

The amount of atrazine adsorption, $\mathrm{q}_{\mathrm{t}}(\mathrm{mg} / \mathrm{g})$, at time $t$ (hr), was calculated by:

$q_{t}=\frac{\left(C_{0}-C_{t}\right) V}{W}$

Where $C_{0}(\mathrm{mg} / \mathrm{L})$ is initial concentration. $C_{t}(\mathrm{mg} / \mathrm{L})$ is concentration at time $t . V(\mathrm{~L})$ is the volume of the solution and $W(\mathrm{~g})$ is the mass of dry adsorbent used.

Figure 4 shows the effect of contact time and initial concentration on atrazine adsorption and it can be realize that the time necessary to reach equilibrium is short. Even longer contract time shows swing line but it can be assumed that reached equilibrium rapidly.

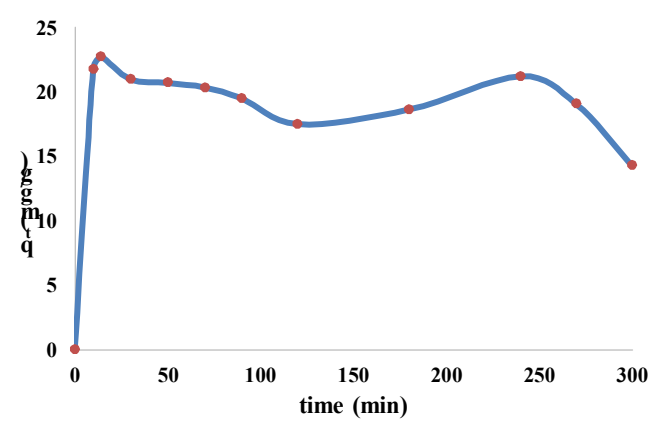

Fig. 4 Effect of contact time and initial concentration on atrazine adsorption.

\subsection{Kinetics analysis}

The modelling of the kinetics of atrazine adsorption was investigated by two common models, namely, the 
pseudo-first order model and pseudo-second-order model. We assumed Lagergren pseudo first order kinetics equation in the linear form as shown below:

$\log \left(q_{e}-q_{t}\right)=\log q_{e}-\left(\frac{k_{1}}{2.303}\right) t$

Where $q_{e}$ and $q_{t}(\mathrm{mg} / \mathrm{g})$ are the amounts of atrazine adsorbed at equilibrium and at time $t$ (hr.), respectively, and $k_{l}(1 / \mathrm{hr})$ is the pseudo first order rate constant. If the plot was found to be linear with good correlation coefficient, indicating that Lagergren's equation is appropriate to atrazine adsorption. But the plot, which is shown in Fig. 5, is not express well by Lagergren pseudo first order kinetics equation and correlation coefficient is 0.59 which is very low.

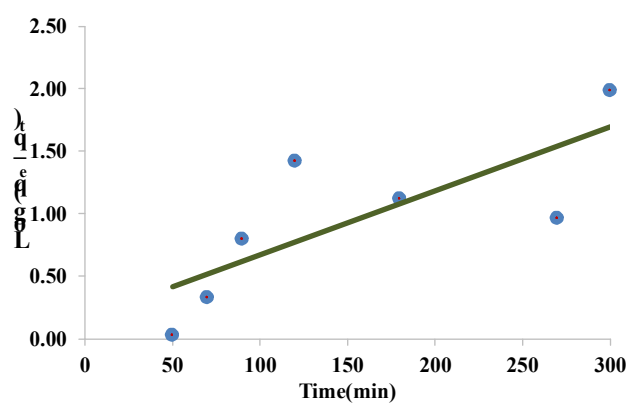

Fig. 5 Pseudo-first-order kinetic for adsorption of atrazine.

Since pseudo first order model is not appropriate for our atrazine adsorption. We also assumed pseudo second order model for this investigation. The pseudo second order kinetics equation is expressed as below:

$\frac{t}{q_{t}}=\frac{1}{k_{2} q_{e}^{2}}+\left(\frac{1}{q_{e}}\right) t$

Where $k_{2}(\mathrm{~g} / \mathrm{mg} \mathrm{h})$ is the rate constant of adsorption, $q_{e}(\mathrm{mg} / \mathrm{g})$ is the amount of atrazine adsorbed at equilibrium and $q_{t}(\mathrm{mg} / \mathrm{g})$ is the amount of atrazine adsorbed at time $t$.

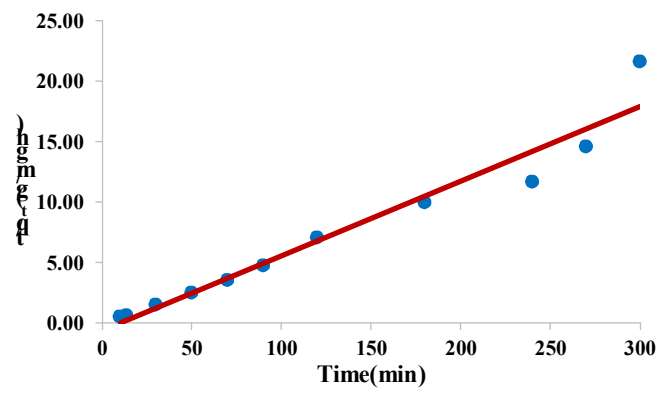

Fig. 6 Pseudo-second-order kinetic for adsorption of atrazine.
Figure 6 shows that the pseudo second order kinetics equation can express well on our atrazine adsorptions with correlation coefficient of 0.95 . It can be indicated that our atrazine adsorption by using synthesized adsorbent from rice straw seem to be chemisorption.

\section{Conclusion}

In comparison with another 3 works [1-3] elemental analyses, $\% \mathrm{C}$ of this work was closed to the data of Abhishek et al. [1], due probably to the similar preparation of rice straw. The result of Suwiwat et al. [3] which chemically activated the raw material by $\mathrm{KOH}$ before pyrolysis and it may affect carbon content of the adsorbent. Considering BET analysis, the adsorbent of this work contained the highest surface area and pore volume revealing that pyrolysis affected to pore volume. Biochar preparation by pyrolysis followed by chemical activation using $\mathrm{H}_{3} \mathrm{PO}_{4}$ were a good precursor for the adsorbent preparation.

Atrazine adsorption was expressed well by the pseudo-second-order kinetics model and agreed with chemisorption. Atrazine was adsorbed rapidly in first 30 min.

\section{References}

1. A. Mandal, N. Singh, T.J. Purakayastha, Sci. Total Environ. 577, 376-385, (2017).

2. J. K. Ratana, M. Kaura, B. Adirajua, Materials Today Proceedings 5, 3334-3345, (2018).

3. S. Sangon, A. J. Hunt, T. M. Attard, P. Mengchang, Y. Ngernyen, N. Supanchaiyamat, Journal of Cleaner Production 172, 1128-1139 (2018). 